\title{
Numerical simulation of scale-up effects of methanol-to-olefins fluidized bed reactors
}

\author{
Lu, Bona; Zhang, Jingyuan; Luo, Hao; Wang, Wei; Li, Hua; Ye, Mao; Liu, Zhongmin; Li, Jinghai
}

Published in:

Chemical Engineering Science

Link to article, DOI:

10.1016/j.ces.2017.05.007

Publication date:

2017

Document Version

Peer reviewed version

Link back to DTU Orbit

Citation (APA):

Lu, B., Zhang, J., Luo, H., Wang, W., Li, H., Ye, M., Liu, Z., \& Li, J. (2017). Numerical simulation of scale-up effects of methanol-to-olefins fluidized bed reactors. Chemical Engineering Science, 171, 244-255.

https://doi.org/10.1016/j.ces.2017.05.007

\section{General rights}

Copyright and moral rights for the publications made accessible in the public portal are retained by the authors and/or other copyright owners and it is a condition of accessing publications that users recognise and abide by the legal requirements associated with these rights.

- Users may download and print one copy of any publication from the public portal for the purpose of private study or research.

- You may not further distribute the material or use it for any profit-making activity or commercial gain

- You may freely distribute the URL identifying the publication in the public portal 


\title{
Numerical simulation of scale-up effects of MTO fluidized bed reactors
}

\author{
Bona Lu*,a,b, Jingyuan Zhang ${ }^{\mathrm{a}, \mathrm{b}}$, Hao Luo ${ }^{\mathrm{b}, \mathrm{c}}$, Wei Wang*,a,b ${ }^{*}$ Hua Lid ${ }^{\mathrm{d}}$, Mao Ye ${ }^{\mathrm{d}}$, Zhongmin Liu ${ }^{\mathrm{d}}$, \\ Jinghai $\mathrm{Li}^{\mathrm{a}}$
}

${ }^{a}$ State Key Laboratory of Multiphase Complex Systems, Institute of Process Engineering, Chinese Academy of Sciences, Beijing 100190, China

${ }^{\mathrm{b}}$ Sino-Danish College, University of Chinese Academy of Sciences, Beijing 100049, China

${ }^{c}$ Department of Chemical and Biochemical Engineering, Technical University of Denmark, 2800 Kongens Lyngby, Denmark

${ }^{d}$ National Engineering Laboratory for MTO, Dalian Institute of Chemical Physics, Chinese Academy of Sciences, Dalian 116023, China

* Corresponding authors. Email addresses: bnlu@ipe.ac.cn (B. Lu), wangwei@ipe.ac.cn (W. Wang).

\begin{abstract}
Scale up of fluidized bed reactors has long been regarded as a big challenge in chemical reaction engineering. While traditional scaling theories are mostly based on hydrodynamics similarity, computational fluid dynamics (CFD) aided approach allows direct coupling between hydrodynamics and reaction factors and is expected to speed up the experiment-based scale-up process with lower cost. In this study, we aim to investigate the scale-up effects through simulations of a series of MTO reactors of different sizes. The two-fluid model and energy-minimization multi-scale (EMMS)-based drag models are combined in simulation. The fluidization characteristics in terms of flow structures, velocity distribution, mass fractions of gaseous product and coke distribution are presented against available experimental data for different-sized reactors. It is found that while typical hydrodynamic features can be reasonably predicted, the prediction of reaction behavior shows growing discrepancy with increasing reactor size. Possible reasons are discussed in the last section along with future work presented for scale-up studies.
\end{abstract}

Keywords: EMMS; scale-up; fluidized bed; simulation; MTO; meso-scale

\section{Introduction}

Scale up of fluidized bed reactors has long been regarded as a big challenge in chemical reaction engineering. Traditional approach focuses on searching scaling laws with various sets of dimensionless numbers (Rüdisüli et al., 2012), where the hydrodynamic similarity is mostly regarded. The coupling between reactions and hydrodynamics is however often neglected (Ye et al., 2015).

Scale-up of the methanol-to-olefins (MTO) reactor that was developed by Dalian Institute of Chemical Physics (DICP) is a good example to understand such challenge (Tian et al., 2015). The MTO is a typical catalytic process, where both reactants and products are in gas phase, and the reactions take place over the surface of catalytic particles. The development of MTO process borrows ideas from the reaction-regeneration configuration of the modern fluid catalytic cracking (FCC) units. However, differences still exist between MTO and FCC processes, which constitute the challenge for scale up (Lu et al., 2016; Ye et al., 2015). Firstly, different catalysts: SAPO-34 
zeolite catalyst with small pores was used in DICP's MTO (or, DMTO) process, and it shows the highest selectivity to ethylene provided with certain coke deposition. In contrast, the FCC process employs the zeolite Y catalyst with larger pores which are not easily blocked by coke deposition. Secondly, different reactors: a densely fluidized bed reactor such as bubbling or turbulent fluidized bed with much longer residence time than that of the FCC riser reactor was preferred for DMTO. Thirdly, both the methanol-to-olefins reactions in reactor and coke burning in regenerator are exothermic, so there is no strict requirement for DMTO on heat-coupling between the reactor and regenerator as in FCC.

As shown in Fig.1, before the commercialization, the scale-up of DMTO has experienced three-stage experiments on the micro-scale (or lab-scale), pilot-scale and demo-scale fluidized bed reactors, respectively. The micro-scale one was operated under the regime of bubbling fluidization in a batch manner without catalyst circulation. Its experimental results were used to evaluate catalyst performance, establish the network of reaction kinetics and help identify the optimal operation window for the design of pilot-scale fluidized bed reactor, such as the optimal gas-catalyst contact time. The operating regime of pilot-scale reactor is the same as the micro-scale one, reflecting their hydrodynamic similarity. In addition, a fluidized bed regenerator, which was connected with the reactor through a standpipe, was especially tested in the pilot-scale reactor to mimic the continual circulation of catalysts in industry. The fluidization performance and stripping attrition of catalyst were preliminarily investigated in this stage. In the demo-scale reactor, however, the operating velocity of gas was increased for high throughput. A different fluidization regime, i.e., turbulent fluidization, was hence adopted. Thus the catalyst circulation, stripping attrition and heat exchange and so on need further study to situate the operation range for commercial setup.

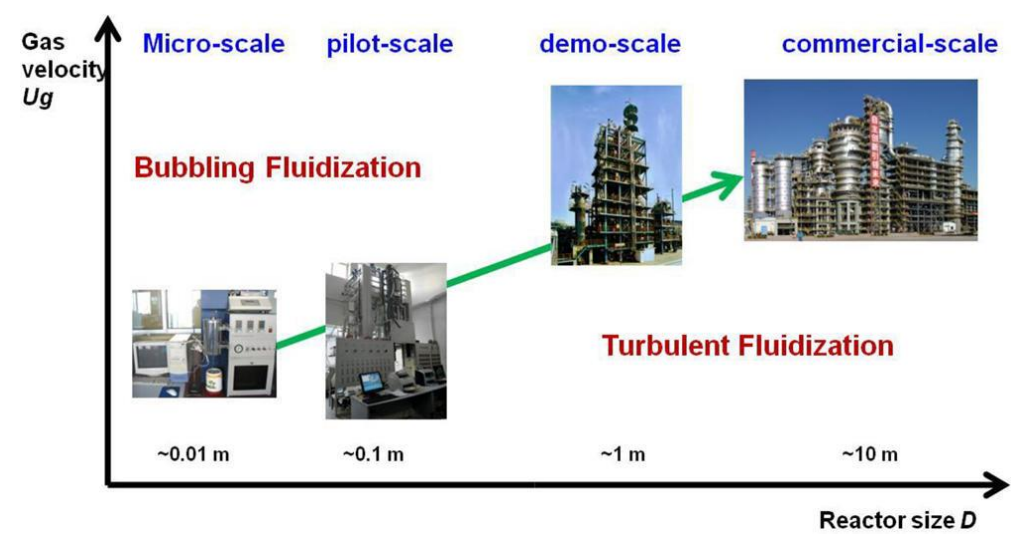

Fig. 1: Scale up of DMTO (DICP's MTO) fluidized bed reactor (Tian et al., 2015).

Such a scale-up is bound to involve the change of flow structures and reaction behaviors, thus requiring a powerful tool to help probe the mechanisms underlying the complex phenomena and shorten the duration of scale-up. Extensive simulation studies on MTO reactors have been reported. Shoenfelder et al. (1994) simulated a lab-scale riser reactor with a one-dimensional hydrodynamic model and lumped reaction kinetics to predict the methanol conversion and selectivity of product. Soundararajan et al. (2001) simulated a circulating fluidized bed (CFB) reactor with a core-annulus hydrodynamic model and lumped kinetics developed by Bos et al.(1995) to investigate the influence of coke deposition and exit geometry on the methanol 
conversion and selectivity of light olefins. Alwahabi and Froment (2004) compared the performance of three types of reactors through simulations coupled with reaction kinetics on SAPO-34 and ZSM-5, respectively, to find out the optimal design and operating conditions.

In recent years, Computational Fluid Dynamics (CFD) has received rapidly growing interest and been widely used for understanding the complex behavior of fluid dynamics and its effects on chemical reactor performance. Chang et al. (2012) simulated the CFB reactor of Soundararajan et al.(2001) by using two-fluid model (TFM) to study the effects of different operating conditions including initial methanol and coke content, reaction temperature, catalyst circulation rate and gas velocity. Zhuang et al. (2014) investigated the hydrodynamics behaviors in a small 2D MTO reactor (width: $0.16 \mathrm{~m}$; height: $0.8 \mathrm{~m}$ ) by employing discrete particle model (DPM) and Bos et al.'s kinetics model. Zhao et al. (2013b) simulated a demo-scale DMTO reactor by using TFM and EMMS/bubbling drag. The predicted distribution of voidage fraction and pressure were in good agreement with experimental data. The time-mean flow parameters were then incorporated into species transport equations to predict the product distribution. Zhu et al. (2016) re-simulated this DMTO reactor by using TFM and a filtered drag model (Milioli et al., 2013) and compared the effects of reaction kinetics model and operating conditions on the prediction. Although these studies are helpful to the determination of reactor type and optimization of parameters, application of CFD in aiding scale-up process is seldom reported.

A CFD-aided scale-up approach can be expected to boost the development of new processes with much lower cost (Xue et al., 2011). On the other hand, as the reactor scale-up is normally associated with flow regime transitions and concomitant change of reaction behaviors, it poses a big challenge to CFD modeling. Firstly, how to account for the meso-scale structures that characterize different flow regimes and their influence on the drag has long been recognized as a key factor to reliable CFD simulations (Wang et al., 2011; Wang et al., 2010; Wang and Chen, 2015). For example, bubbles in bubbling fluidization, clusters in the so-called fast fluidization and shapeless voids in turbulent fluidization are found to be crucial to correctly model the drag (Hong et al., 2013; Shi et al., 2011; Wang and Li, 2007; Yang et al., 2003). However, whether a meso-scale model that is applicable in one regime (say, the EMMS/bubbling drag for bubbling fluidization) can be applied in another one (say, turbulent fluidization) requires further exploration Secondly, the interplay between flow structures and catalytic reactions should be considered in modeling. For the reactive simulation of a large reactor, various lumped-species kinetics models are widely used (Gan et al., 2011; Lopes et al., 2011; Lu et al., 2013a; Lu et al., 2016; Shah et al., 2016), where a group of components with similar chemical properties are treated as one lump to reduce computational demand. However, the reaction kinetics parameters, which are generally obtained from experiments over micro-scale reactors, are hardly termed the "intrinsic" ones where the influence of inner and outer diffusions should be strictly excluded in experiments. Whether such a lumped reaction kinetics model is suitable for larger-scale reactors running over different flow regime remains an open problem (Liu et al., 2015; Wang et al., 2011). Thirdly, to simulate a large reactor economically, coarse-grid resolution with adequate accuracy is always necessary. However, even with coarse-grid resolution, it is still a formidable task to simulate a system with long residence time that takes long computing time to evolve as in the case of coke deposition in MTO reactors. In our previous report (Lu et al., 2016), a reactor model was proposed to help speed up the simulation by providing the initial distribution of coke for the reactive simulation of a pilot-scale MTO reactor. Whether such measure is effective for speeding up simulations of 
larger-scale MTO reactors needs further investigation.

In this article, we aim to investigate the scale-up effects through CFD simulations of a series of DMTO reactors of different size. The basic governing equations and meso-scale closure models under different fluidization regimes are first presented with emphasis on grid-dependency analysis, followed by a series of reactive simulations of different DMTO reactors. The variation of quantities such as flow structures, solid velocity, and product yield and coke distribution are discussed to reflect the effect of reactor size. Finally, the perspective is presented on future work targeting the simulations for scale-up studies.

\section{Model and settings}

\subsection{DMTO fluidized bed reactors}

Fig. 2 shows the geometries of DMTO reactors of different size ranging from the micro-scale to commercial scale. The micro-scale bed with $0.019 \mathrm{~m} \mathrm{I.D.} \mathrm{and} \mathrm{height} \mathrm{of} 0.33 \mathrm{~m}$ is operated in bubbling fluidization with no circulation of catalysts. For the pilot-scale reactor, the main reaction zone is a bubbling reactor with $0.261 \mathrm{~m}$ I.D. and height of $1.347 \mathrm{~m}$, and the sedimentation section and lift tube are added to assist the circulation of catalysts. For the demo-scale reactor, the main reaction zone is enlarged to a cylindrical body with $1.25 \mathrm{~m}$ I.D and height of $4 \mathrm{~m}$. For the industrial reactor, the main reaction zone is further enlarged to $10.5 \mathrm{~m} \mathrm{I.D}$ and height of $8 \mathrm{~m}$. The reactants are mixture of methanol and steam that are blown into the reactor below the gas distributor mounted at the bottom of the main reaction zone, and gaseous products are released from the top exit. Besides the micro-scale bed, spent catalysts are discharged at the bottom of the lift tube which is fluidized by a small quantity of lift steam, and then transported to the regenerator for restoring the activity. Table 1 lists the operating conditions for these four DMTO reactors.

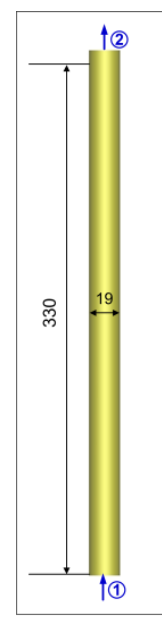

Micro-scale

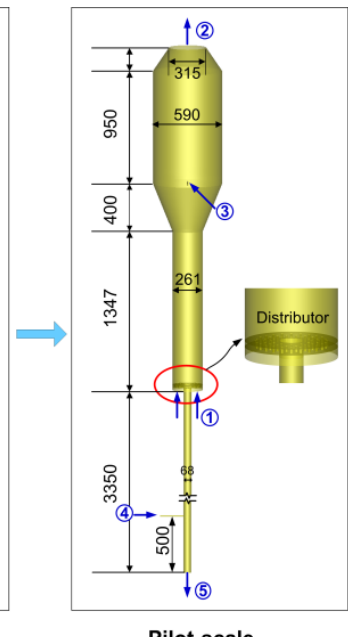

Pilot-scale

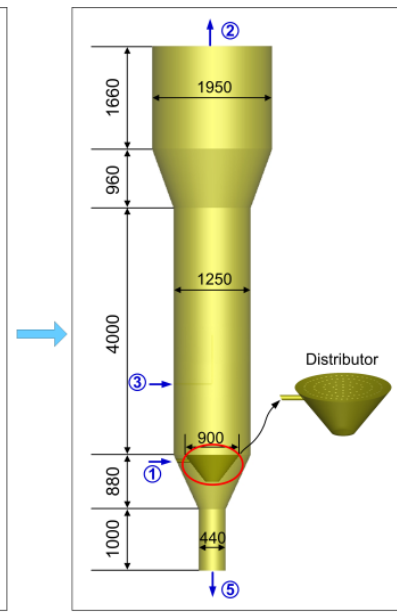

Demo-scale

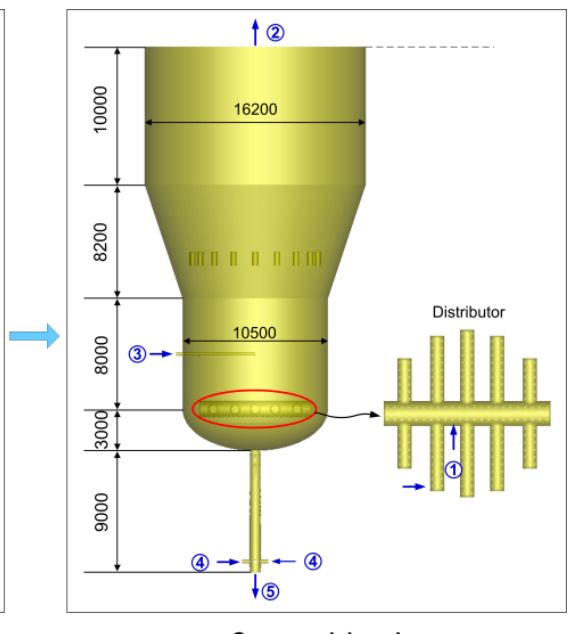

Commercial-scale

Fig. 2. The geometries of DMTO reactors of different size: (1) inlet for methanol and steam (mass flow inlet); (2) outlet for gaseous product (pressure outlet); (3)inlet for fresh catalyst (velocity inlet); (4) inlet for steam (5)outlet for spent catalyst (velocity inlet). 
Table 1. Operating conditions for four DMTO reactors

\begin{tabular}{lcccc}
\hline Operating parameters & Micro-scale & Pilot-scale & Demo-scale & Commercial-scale \\
\hline Temperature, $\mathrm{K}$ & 723 & 738 & 773 & 748 \\
Gauge pressure at top exit, MPa & 0 & 0.024 & 0.103 & 0.108 \\
Inflow rate of methanol, $\mathrm{kg} / \mathrm{h}$ & 0.0135 & 18 & 2032 & 241000 \\
Inflow rate of steam, $\mathrm{kg} / \mathrm{h}$ & 0.02025 & 9 & 610 & 60250 \\
Fresh catalyst inflow rate, $\mathrm{kg} / \mathrm{h}$ & 0 & 8.8 & 351 & 42000 \\
Catalyst inventory in reactor, $\mathrm{kg}$ & 0.009 & 9 & 501 & 56000 \\
\hline
\end{tabular}

\subsection{Governing equations and constitutive relations}

The Eulerian multiphase flow model (or, TFM) in ANSYS Fluent ${ }^{\circledR}$ version 15 with kinetic theory for granular flow is applied in this work (ANSYS, 2013), and it has been commonly used to simulate large reactors. To couple the dynamic flow and reactions simultaneously, the species and energy transport equations are turned on to take into account the chemical reactions. The energy transport equations are not used since all the cases are treated to be isothermal. The following gives the relevant equations.

\section{Continuity equation for phase $q(q=\mathrm{g}, \mathrm{s} ; p=\mathrm{s}, \mathrm{g})$ :}

$$
\frac{\partial}{\partial t}\left(\varepsilon_{q} \rho_{q}\right)+\nabla \cdot\left(\varepsilon_{q} \rho_{q} \boldsymbol{u}_{q}\right)=n k_{p q}-n k_{q p},
$$

where $u_{q}$ is the velocity of phase $q, n_{p q}$ the mass transfer term from the phase $p$ to phase $q$.

\section{Momentum balance equation for gas and solid phases:}

$$
\begin{aligned}
& \frac{\partial}{\partial t}\left(\varepsilon_{\mathrm{g}} \rho_{\mathrm{g}} \boldsymbol{u}_{\mathrm{g}}\right)+\nabla \cdot\left(\varepsilon_{\mathrm{g}} \rho_{\mathrm{g}} \boldsymbol{u}_{\mathrm{g}} \boldsymbol{u}_{\mathrm{g}}\right)=-\varepsilon_{\mathrm{g}} \nabla p+\nabla \cdot \tau_{\mathrm{g}}+\varepsilon_{\mathrm{g}} \rho_{\mathrm{g}} \boldsymbol{g}+\left(\boldsymbol{u}_{\mathrm{s}}-\boldsymbol{u}_{\mathrm{g}}\right) \beta+\left(n \&_{\mathrm{gg}} \boldsymbol{u}_{\mathrm{sg}}-n k_{\mathrm{gg}}^{\&_{\mathrm{gs}}} \boldsymbol{u}_{\mathrm{gs}}\right), \\
& \frac{\partial}{\partial t}\left(\varepsilon_{\mathrm{s}} \rho_{\mathrm{s}} \boldsymbol{u}_{\mathrm{s}}\right)+\nabla \cdot\left(\varepsilon_{\mathrm{s}} \rho_{\mathrm{s}} \boldsymbol{u}_{\mathrm{s}} \boldsymbol{u}_{\mathrm{s}}\right)=-\varepsilon_{\mathrm{s}} \nabla p-\nabla p_{\mathrm{s}}+\nabla \cdot \boldsymbol{\tau}_{\mathrm{s}}+\varepsilon_{\mathrm{s}} \rho_{\mathrm{s}} \boldsymbol{g}-\left(\boldsymbol{u}_{\mathrm{s}}-\boldsymbol{u}_{\mathrm{g}}\right) \beta+\left(n \alpha_{\mathrm{gs}} \boldsymbol{u}_{\mathrm{gs}}-n \alpha_{\mathrm{sg}}^{\&} \boldsymbol{u}_{\mathrm{sg}}\right),
\end{aligned}
$$

where $\tau$ is the stress tensor $(q=\mathrm{g}, \mathrm{s})$,

$$
\boldsymbol{\tau}_{q}=\varepsilon_{q} \mu_{q}\left[\nabla \boldsymbol{u}_{q}+\left(\nabla \boldsymbol{u}_{q}\right)^{\mathrm{T}}\right]+\varepsilon_{q}\left(\lambda_{q}-\frac{2}{3} \mu_{q}\right) \nabla \cdot \boldsymbol{u}_{q} \boldsymbol{I} .
$$

Here $p$ is the gas pressure shared by all phases. Note that $\left(\boldsymbol{u}_{\mathrm{s}}-\boldsymbol{u}_{\mathrm{g}}\right) \beta$ on the right hand side is the drag force in gas-solid fluidized beds. The other interactions such as lift force, virtual mass force are not considered here. $\boldsymbol{u}_{\mathrm{pq}}$ and $\boldsymbol{u}_{\mathrm{qp}}$ are the interphase velocities. If $n_{p q}^{\&}>0, \boldsymbol{u}_{\mathrm{pq}}=\boldsymbol{u}_{\mathrm{p}}$, else $\boldsymbol{u}_{\mathrm{pq}}=\boldsymbol{u}_{\mathrm{q}}$; likewise, If $\boldsymbol{n}_{q p}^{k}>0$, then $\boldsymbol{u}_{\mathrm{qp}}=\boldsymbol{u}_{\mathrm{q}}$, else $\boldsymbol{u}_{\mathrm{qp}}=\boldsymbol{u}_{\mathrm{p}}$.

\section{Chemical species balance equation in phase $q$ :}

$$
\frac{\partial}{\partial t}\left(\rho_{q} \varepsilon_{q} Y_{q, i}\right)+\nabla \cdot\left(\rho_{q} \varepsilon_{q} \boldsymbol{u}_{q} Y_{q, i}\right)=-\nabla \cdot \varepsilon_{q} \boldsymbol{J}_{q, i}+\varepsilon_{q} R_{q, i}+\varepsilon_{q} S_{q, i}+\mathfrak{R},
$$

where $\boldsymbol{J}$ is the diffusion flux of species $i, R_{q, i}$ the net rate of production of homogeneous species $i$ 
by chemical reaction for phase $q$, and $\Re$ the heterogeneous reaction rate. In addition, $S_{q, i}$ is the rate of creation by addition from any user-defined sources. In this simulation, the MTO reactions will be written into equations through user-defined sources while leaving $R_{q, i}$ and $\Re$ un-computed.

In this set of averaged conservation equations for the mass, momentum and energy for each phase, the gas-particle drag force, solid-phase stress, interphase mass and heat transfer and the reaction source terms need to be closed. Nowadays, modeling of momentum interaction between the gas and solid phases, mass/heat transfer as well as reaction rate with consideration of meso-scale structures has become hot topics in both academic and industry communities. And particular attention is paid to the modeling of drag coefficient due to its great influence on gas-solid flow behavior. In what follows we will present the drag modeling based on the energy-minimization multi-scale (EMMS) method (Li and Kwauk, 1994).

\subsection{EMMS Drag}

The EMMS model was originally proposed by Li and Kwauk (1994) for describing the heterogeneous state of flow in a circulating fluidized bed. To couple it with CFD, Yang et al. (2003) and Wang and Li (2007) extended this model by introducing accelerations into the EMMS, thereon developed the cluster-based EMMS drag model. In particular, the EMMS/matrix drag model features a two-step scheme, and the drag correction factor in terms of the heterogeneity index $H_{\mathrm{D}}$ was correlated as a function of both voidage and slip velocity. This additional dependence on the slip velocity enables not only improved prediction of CFD simulation but also an advantage of less sensitivity to the mesh resolution (Lu et al., 2009, 2011). That paves a solid base to coarse-grid simulation of large circulating fluidized beds with the EMMS/matrix drag (Lu et al., 2013b). Shi et al. (2011) and Hong et al. (2013) further extended the EMMS drag model to the realm of densely fluidized beds by introducing bubbles in place of particle clusters to characterize the meso-scale structure. The heterogeneous flow in a bubbling fluidized bed was thus resolved into three sub-systems or phases, i.e. the dense phase (emulsion), the dilute phase inside bubbles, and their meso-scale interphase. There were seven conservation equations and a stability condition raised to close ten variables, i.e., $U_{\mathrm{gc}}, U_{\mathrm{sc}}, a_{\mathrm{sc}}$, and $\varepsilon_{\mathrm{gc}}$ for the dense phase, $U_{\mathrm{gc}}$, $U_{\mathrm{gf}}, \varepsilon_{\mathrm{gf}}$ and $a_{\mathrm{gf}}$ for the dilute phase, and the volume fraction of dense phase $(f)$ and the bubble size $\left(d_{\mathrm{b}}\right)$ for the meso-scale interphase. This EMMS/bubbling drag model has been coupled with TFM and found successful in simulation of lab-scale bubbling fluidized beds (Hong et al., 2014).

Similar to the approach used in the EMMS/matrix drag model, recently we introduced the two-step scheme into the EMMS/bubbling drag model (Luo et al., 2017). Its heterogeneity index $H_{\mathrm{D}}$ is thus also extended to be a function of both slip velocity and voidage. Testing of this new drag model, as detailed in Luo et al. (2017), confirmed again its advantage in both accuracy and less dependency on mesh resolution, for bubbling and turbulent fluidized beds both in lab scale. In this work, we will test this two-step scheme of EMMS/bubbling drag model in simulation of industrial DMTO reactors.

The EMMS-based drag coefficient can be written by

$$
\beta_{\text {EMMS }}=\frac{3}{4} C_{\mathrm{D} 0} \frac{\varepsilon_{\mathrm{s}} \varepsilon_{\mathrm{g}} \rho_{\mathrm{g}}\left|u_{\mathrm{g}}-u_{\mathrm{s}}\right|}{d_{\mathrm{p}}} \varepsilon_{\mathrm{g}}^{-2.65} H_{\mathrm{D}},
$$

where $\mathrm{C}_{\mathrm{D} 0}$ denotes the standard drag coefficient for an individual particle and reads 


$$
C_{\mathrm{D} 0}=\frac{24\left(1+0.15 \operatorname{Re}^{0.687}\right)}{\operatorname{Re}}, \quad \operatorname{Re}<1000 ; C_{\mathrm{D} 0}=0.44, \quad R e \geq 1000 .
$$

Here the heterogeneity index $H_{\mathrm{D}}$ is defined by $\beta_{\mathrm{EMMS}} / \beta_{0}$, where $\beta_{0}$ refers to Wen and Yu drag (Wen and $\mathrm{Yu}, 1966)$ without considering the heterogeneous structure. For the micro-scale, pilot-scale and demo-scale reactors where the superficial gas velocity is low and there is few solid entrained out of the bed, we use the EMMS/bubbling drag with zero solid flux, which can be generated by using software EMMS®. For the commercial-scale reactor with relatively high gas velocity, there may exist larger solid entrainment that is however hard to measure in industrial operation. Hence we employ the steady-state EMMS model ( $\mathrm{Li}$ and Kwauk, 1994) to estimate the solid flux first and then determine $H_{\mathrm{D}}$ from the two-step version of EMMS/bubbling drag model (Luo et al., 2017). As shown in Fig.3, when the solid inventory and the superficial gas velocity, as listed in Table 1, are specified with $56,000 \mathrm{~kg}$ and $1.35 \mathrm{~m} / \mathrm{s}$, respectively, we can determine the solid flux as about $4 \mathrm{~kg} /\left(\mathrm{m}^{2} \mathrm{~s}\right)$. The fitting functions of the EMMS drag in all cases are given in Appendix A.

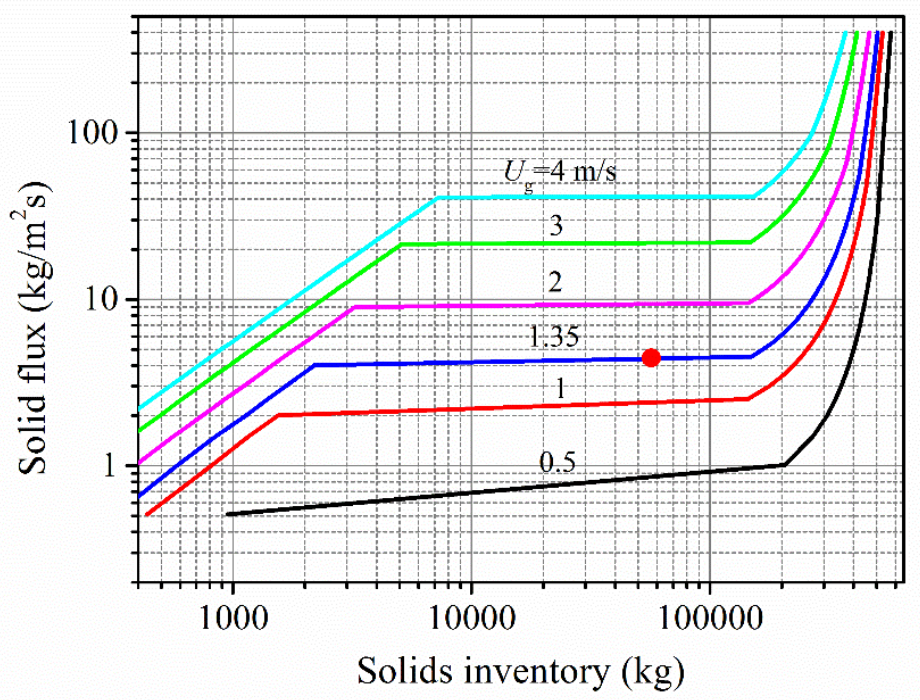

Fig. 3. The flow regime map of commercial-scale DMTO reactor $\left(U_{\mathrm{g}}=1.35 \mathrm{~m} / \mathrm{s}, \mu_{\mathrm{g}}=2.5627 \times 10^{-5}\right.$ Pa $\left.\cdot \mathrm{s}, \rho_{\mathrm{g}}=0.7166 \mathrm{~kg} / \mathrm{m}^{3}, d_{\mathrm{p}}=97 \mu \mathrm{m}, \rho_{\mathrm{s}}=1500 \mathrm{~kg} / \mathrm{m}^{3}\right)$.

\subsection{DMTO reaction kinetics}

Although detailed kinetic models have been developed for MTO process, lumped models have attracted much wider attention for engineering computation because of their simplicity and acceptable reliability. In this study, all simulations for four MTO reactors employ the same lumped kinetics model which was constructed on experiments of micro-scale fluidized bed (Lu et al., 2016).

The formation rate of each lump, $R_{\mathrm{i}}\left(i=\mathrm{CH}_{4}, \mathrm{C}_{2} \mathrm{H}_{4}, \mathrm{C}_{3} \mathrm{H}_{6}, \mathrm{C}_{3} \mathrm{H}_{8}, \mathrm{C}_{4} \mathrm{H}_{8}, \mathrm{C}_{5} \mathrm{H}_{10}, \mathrm{MeOH}\right.$ and $\mathrm{H}_{2} \mathrm{O}$ ), where $\mathrm{MeOH}$ refers to methanol, is given by

$$
R_{i}=v_{i} k_{i} \varphi_{i} C_{\mathrm{MeOH}} M_{i},
$$

The total reaction rates for methanol and water read 


$$
\begin{aligned}
& R_{\mathrm{MeOH}}=-\left(\sum_{1}^{6} v_{i} k_{i} \varphi_{i}\right) C_{\mathrm{MeOH}} M_{\mathrm{MeOH}}, \\
& R_{\mathrm{H}_{2} \mathrm{O}}=\left(\sum_{1}^{6} v_{i} k_{i} \varphi_{i}\right) C_{\mathrm{MeOH}} M_{\mathrm{H}_{2} \mathrm{O}},
\end{aligned}
$$

where $v_{\mathrm{i}}$ is the stoichiometric number; $C_{\mathrm{MeOH}}$ denotes the methanol concentration, $(\mathrm{mol} / \mathrm{L}) ; M$ denotes the molar weight, $\mathrm{g} / \mathrm{mol} ; k_{\mathrm{i}}$ is the reaction rate constant corresponding to lump $i,\left(\mathrm{~L} / \mathrm{g}_{\text {cat }} / \mathrm{s}\right)$ and $\varphi_{i}$ is a selective deactivition function to quantify the product selectivity and abrupt change in the MTO process, as follows:

$$
\varphi_{i}=\frac{A}{1+B \exp \left(D \times\left(w_{\text {coke }}-E\right)\right)} \exp \left(-\alpha_{i} w_{\text {coke }}\right) .
$$

Here $A, B, D$ and $E$ are constants, and $w_{\text {coke }}$ the coke content. The rate constants $k_{\mathrm{i}}$ and $\alpha_{\mathrm{i}}$ are referred to Lu et al. (2016).

\subsection{Simulation settings}

The boundary settings for the DMTO reactors are also shown in Fig.2. The geometry and cells are generated by using Gambit ${ }^{\circledR} 2.4$. For the micro-scale DMTO reactor, 9180 hexahedral cells are uniformly distributed throughout the whole bed. While for the other DMTO reactors, hexahedral cells are generated for the most part of computational zones, and tetrahedral cells are employed for the regions near the distributor and inlet or outlet tubes. The number of cells are 346214,368443 and 537210 for the pilot-, demo- and commercial-scale reactors, respectively, and most of them are deployed for meshing the region near the distributor where the MTO reactions mostly take place (Zhao et al., 2013b). Such resolution is acceptable as indicated in our previous work (Lu et al., 2016; Lu et al., 2009; Luo et al., 2017) that the coarse-grid simulation of fluidized beds with the EMMS drag, in particular the two-step version, allowed reasonable predictions. The original configuration of gas distributors are simplified in simulations. Sieve and sintered plates in the pilot-scale and demo-scale reactors are replaced by perforated plates with opening ratio of $5 \%$ and $2.2 \%$ respectively. The multi-pipe distributor in the commercial-scale reactor is also simplified by reducing the pipe number while its opening is set as the inlet boundary and the opening ratio is kept $3.8 \%$ unchanged.

In all simulation cases, the mass flow inlet is prescribed for both the methanol-steam mixture inlet and the steam inlet. The velocity inlet is specified for the catalyst inlet and the bottom catalyst outlet. The mass flow rates at the top exit will be monitored and recycled to the reactors to keep a constant solid inventory in the bed, which is the so-called CFBC mode of operation (Mei et al., 2017). The no-slip wall boundary is set for both the gas and solid phases. Both gas and solid phases are treated as mixtures in simulations. There are nine species in the gas mixture, i.e. $\mathrm{CO}_{2}$, $\mathrm{CH}_{4}, \mathrm{C}_{2} \mathrm{H}_{4}, \mathrm{C}_{3} \mathrm{H}_{6}, \mathrm{C}_{3} \mathrm{H}_{8}, \mathrm{C}_{4} \mathrm{H}_{8}, \mathrm{C}_{5} \mathrm{H}_{10}, \mathrm{H}_{2} \mathrm{O}$ and $\mathrm{MeOH}$. In particular, $\mathrm{CO}_{2}$ is introduced intentionally as an "inert" gas and the last species for the sake of numerical stability. The solid phase has two species of coke and catalyst, where the same heat capacity $(1220 \mathrm{~J} /(\mathrm{kg} \cdot \mathrm{K})$ and thermal conductivity $(0.0454 \mathrm{~W} /(\mathrm{m} \cdot \mathrm{K}))$ are specified. The mass changes of the coke and all the gaseous species except $\mathrm{CO}_{2}$ are expressed in the form of source term (the third term) on the right hand side of the species transport equation. In addition, the mass exchange between the gas and 
solid phases arising from the production of coke should be considered into the mass conservation equations (Eq.1). The catalyst diameter and density are $97 \mu \mathrm{m}$ and $1500 \mathrm{~kg} / \mathrm{m}^{3}$, respectively. The molecular weight of each gas species is obtained from NIST database (http://webbook.nist.gov/chemistry). The viscosities are taken from Tong and Li (1982), and UDFs (User-defined-functions) for the viscosity of each gaseous species are provided in supplementary documents. More detailed settings of reactive simulations can be referred to Lu et al (2016).

It has been reported that a reasonable initial distribution can help speed up hydrodynamic simulations. Liu et al. (2011) and Zhao et al. (2013a) found that if the initial distribution of solid volume fraction are specified with the steady-state predictions from the EMMS model, the simulation time elapsed from the initialization to the dynamically steady state of flow can be greatly reduced. Likewise, for reactive gas-solid flow in DMTO reactor where the catalyst particles need long residence time to accumulate enough coke deposition for favoring production of ethylene and propylene, a reasonable steady-state distribution of the reactants are much expected to accelerate such reactive simulations. Our previous work (Lu et al., 2016) established a continuous stirred tank reactor (CSTR) model to initialize the distribution of reactants and products with their steady-state values for the pilot-scale DMTO reactor. It was found such initial distribution help greatly speed up our CFD simulations. As shown in Fig. 4, when the simulation starts with fresh catalysts, the coke content amounts to about $0.08 \%$ after an elapse of $50 \mathrm{~s}$. The ratio of $\mathrm{C}_{2} \mathrm{H}_{4}$ to $\mathrm{C}_{3} \mathrm{H}_{6}$ increases with coke content, but is far less than the measurement (1.24) yet at the end of $50 \mathrm{~s}$. When initialized with the CSTR estimation, the coke content rises rapidly and then levels off and the ratio of $\mathrm{C}_{2} \mathrm{H}_{4}$ to $\mathrm{C}_{3} \mathrm{H}_{6}$ approaches quickly to 1.21 that is close to the experimental data of 1.24 .
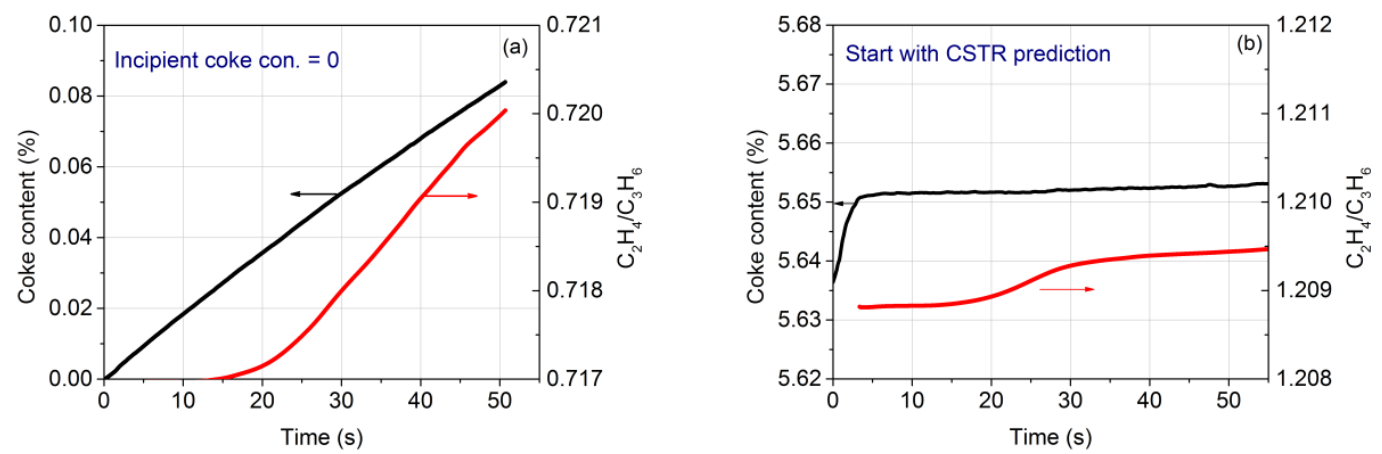

Fig. 4. The time-dependent variation of the mass-weighted-average coke content and the ratio of $\mathrm{C}_{2} \mathrm{H}_{4}$

to $\mathrm{C}_{3} \mathrm{H}_{6}$ in simulation of the pilot-scale reactor, adapted from Lu et al. (2016).

In this study, for the micro-scale fluidized bed, the fresh catalysts without coke deposition are uniformly distributed at the beginning with the incipient fluidization voidage. For the other DMTO reactors, the CSTR prediction is used to initialize the simulation. Table 2 summarizes the predicted concentrations of the CSTR model. 
Table 2. Mass fractions of gaseous products and other quantities predicted by using CSTR model (The mass fractions are recalculated by removing $\mathrm{H}_{2} \mathrm{O}$ and methanol)

\begin{tabular}{llll}
\hline & Pilot-scale & Demo-scale & Commercial-scale \\
\hline$Y_{\mathrm{CH} 4}$ & 0.01468 & 0.03011 & 0.0184 \\
$Y_{\mathrm{C} 2 \mathrm{H} 4}$ & 0.4432 & 0.53883 & 0.5174 \\
$Y_{\mathrm{C} 3 \mathrm{H} 6}$ & 0.3673 & 0.31233 & 0.3307 \\
$Y_{\mathrm{C} 3 \mathrm{H} 8}$ & 0.02874 & 0.01367 & 0.0168 \\
$Y_{\mathrm{C} 4}$ & 0.1073 & 0.07514 & 0.0828 \\
$Y_{\mathrm{C} 5}$ & 0.03877 & 0.02991 & 0.0340 \\
$w_{\mathrm{coke}}(\%)$ & 5.65 & 7.41 & 6.71 \\
$\eta_{\mathrm{MeoH}}(\%)$ & 98.3126 & 92.88 & 93.92 \\
\hline
\end{tabular}

\section{CFD simulation results}

Given the initial distribution of coke and solid inventory, once the simulation starts, the total solids inventory in the DMTO reactor keeps constant as the solids mass flow out is set equal to the solid mass flow in. The simulation for the micro-scale reactor was performed for more than 4 minutes, and the other cases more than $100 \mathrm{~s}$. The time-dependent variation of solid concentration in the reaction zones and product concentration at the outlet is monitored for time-average analysis after reaching steady state.

\subsection{Hydrodynamic distributions}

Fig.5 shows the instantaneous distribution of solid volume fraction across the whole bed. A relatively uniform flow structure is captured in the micro-scale fluidized bed where the averaged superficial gas velocity is about $0.1 \mathrm{~m} / \mathrm{s}$. More heterogeneous flow structures appear in larger MTO reactors with increasing gas velocity. A typical bubbling flow structure is evidently observed in the pilot-scale reactor, and the turbulent fluidization with a much diffuse upper bed surface is predicted for the demo-scale reactor. While for the commercial-scale reactor with higher velocity, the bubbles are replaced with particle clusters. The axial profiles of solid concentration for these four cases are compared in Fig. 6. In the upper reaction zones, almost no solid exists for the micro-scale, pilot-scale and demo-scale reactors, while for the commercial-scale reactor, solids can be found even at the top with volume fraction of about 0.02 , indicating obvious entrainment. From the solid flux monitored at the height of $4 \mathrm{~m}$, as shown in Fig.7, we can see that after $20 \mathrm{~s}$ the solid flux fluctuates around the mean value of about $2.85 \mathrm{~kg} /\left(\mathrm{m}^{2} \mathrm{~s}\right)$, which is close to the prediction of EMMS model $\left(4 \mathrm{~kg} /\left(\mathrm{m}^{2} \mathrm{~s}\right)\right)$ as discussed in section 2.3 . 


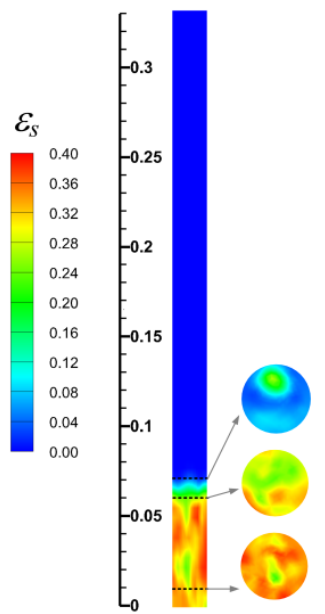

(a)

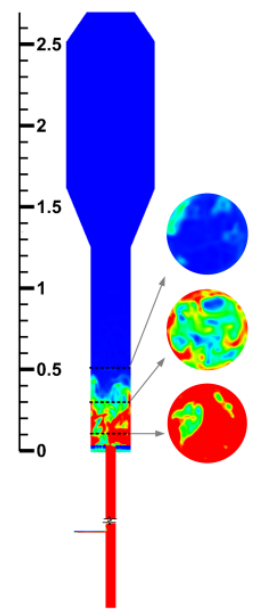

(b)

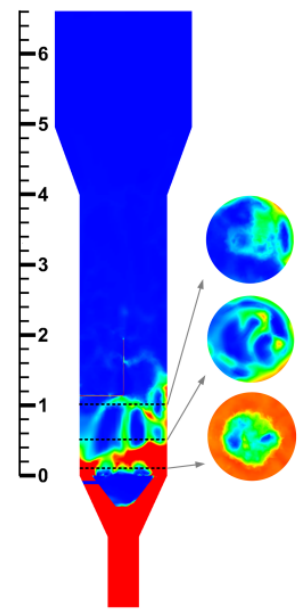

(c)

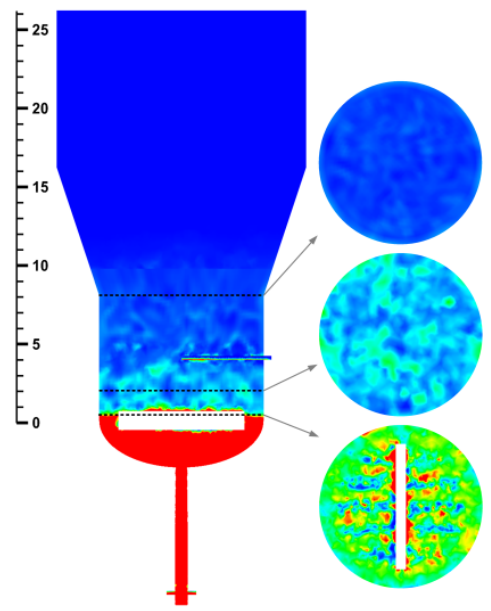

(d)

Fig. 5. Instantaneous distribution of solid concentration on the axial cross section: (a) micro-scale reactor; (b) pilot-scale reactor; (c) demo-scale reactor; (d) commercial-scale reactor.

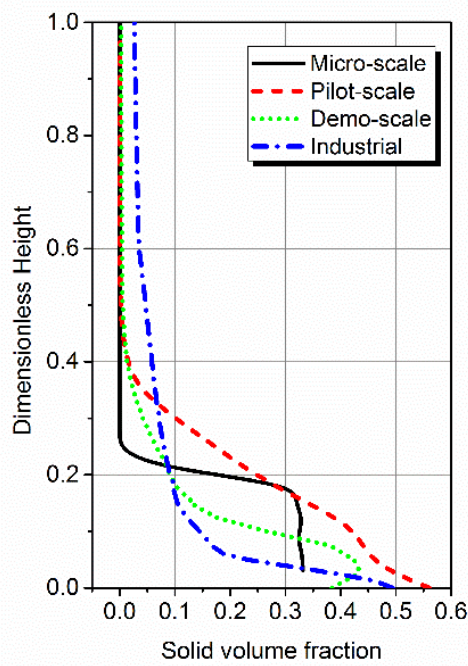

Fig. 6. The axial profiles of mean solid concentration in the reaction zones of four DMTO reactors.

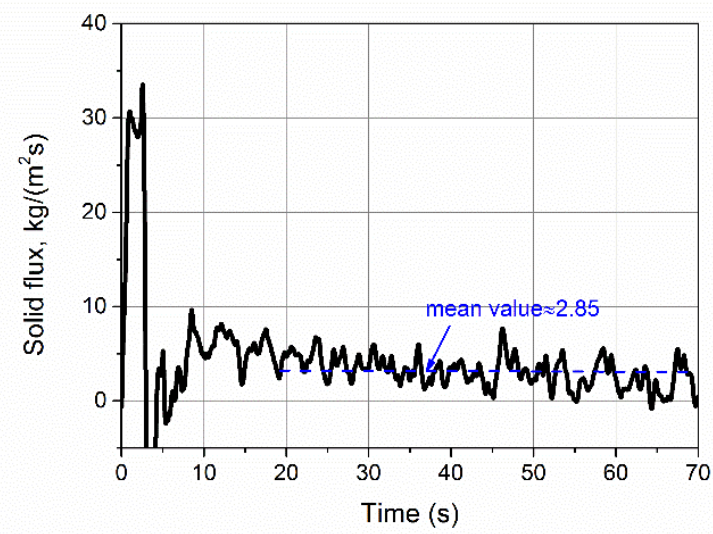

Fig.7. The variation of solid flux (at the elevation of $4 \mathrm{~m}$ above the distributor) with time for the industrial MTO reactor 
Fig. 8 shows instantaneous distribution of the magnitude of the axial solid velocity across the whole bed. In the micro-scale reactor, the axial solid velocity varies in a relatively small range due to the lower operating velocity and uniform flow structure. As gas velocity increases for the cases of three larger-scale reactors, the axial solid velocity displays a wider distribution and more negative velocities appear near the wall. It should be noted that for the commercial reactor, much lower velocity is found below the distributor than that above the distributor, and some of methanol and stream are injected downward through the gas distributor.

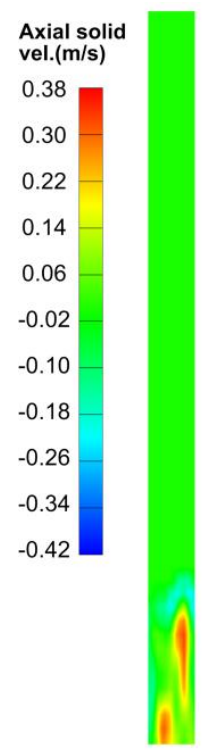

(a)

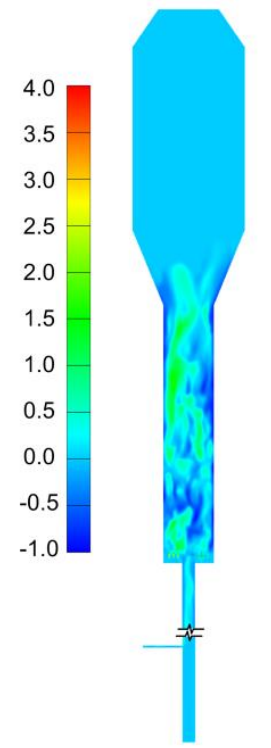

(b)

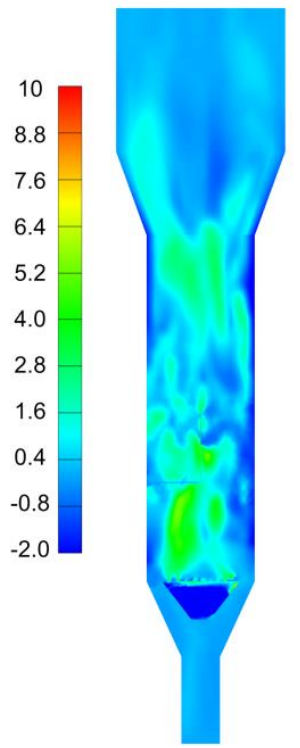

(c)

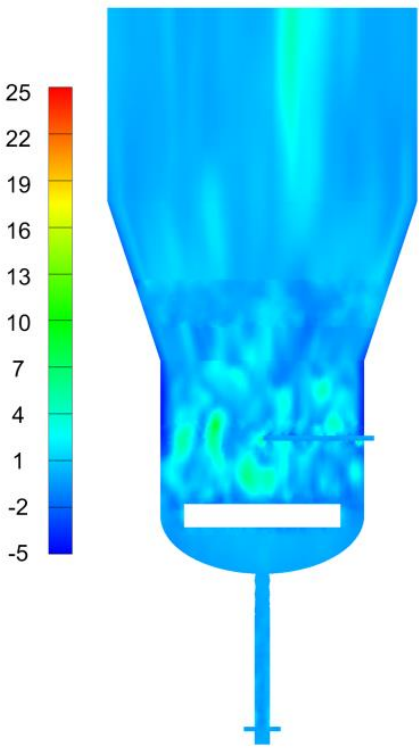

(d)

Fig. 8. Instantaneous distribution of axial solid velocity on the axial cross section: (a) micro-scale reactor; (b) pilot-scale reactor; (c) demo-scale reactor; (d) commercial-scale reactor.

\subsection{Distribution of gaseous products}

Fig. 9 shows the predicted gaseous product at the reactor outlet against experimental data. The simulation results for both micro-scale and pilot-scale reactors show good agreement with the experimental data, while big discrepancy exists between simulation and measurement for both demo-scale and commercial reactors in the sense that ethylene is over-predicted and propylene is under-predicted. Table 3 compares prediction and experimental data in terms of the mass fractions of gaseous products, selectivity of ethylene and propylene, conversion of methanol as well as coke content. In contrast to the cases of the micro-scale and pilot-scale reactors, simulation fails to predict the ratio of $\mathrm{C}_{2} \mathrm{H}_{4}$ to $\mathrm{C}_{3} \mathrm{H}_{6}$ for the cases of demo-scale and commercial reactors (the relative error exceeds 50\%). In addition, it is interesting to note that all simulations predict successfully the overall conversion of methanol which is under-estimated by the CSTR model. Probably, the dynamic evolution of flow and reactions in CFD simulation after the initialization prolongs the residence of methanol and makes it completely consumed in the whole bed, but the other quantities such as coke content and mass fraction of each product change a little compared to the initial value as listed in Table 2. In what follows we concentrate on the simulations of pilot-scale and commercial reactors to further analyze their differences. 

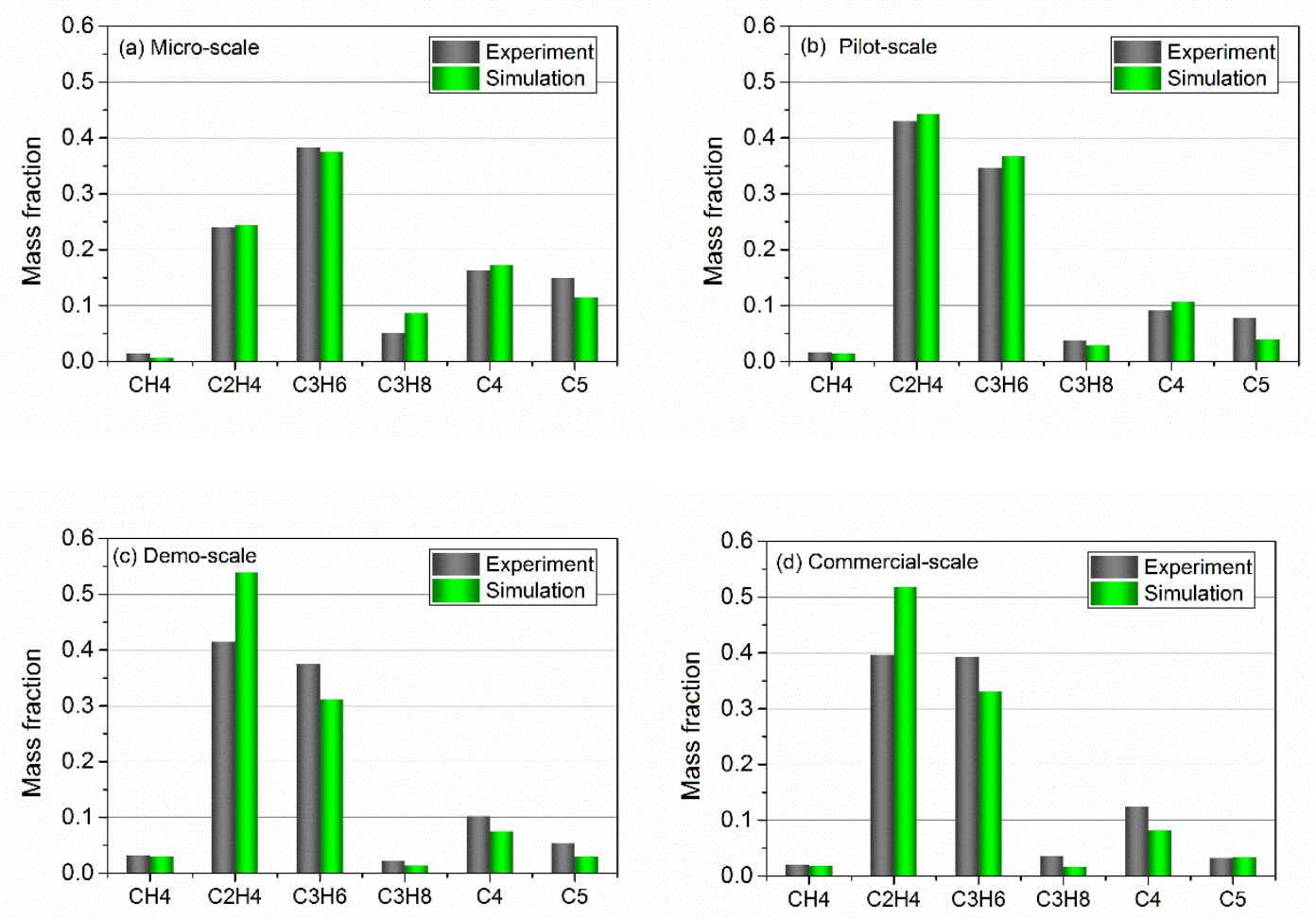

Fig. 9. Mass fraction of gaseous product obtained from CFD simulation and experiment (the mass fractions are normalized after removing $\mathrm{H}_{2} \mathrm{O}$, methanol and $\mathrm{CO}_{2}$ ).

Table 3. Mass fractions of gaseous products and other quantities: comparison between prediction and experimental data (mass fractions are normalized after removing $\mathrm{H}_{2} \mathrm{O}$, methanol and $\mathrm{CO}_{2}$ ).

\begin{tabular}{|c|c|c|c|c|c|c|c|c|}
\hline & \multicolumn{2}{|c|}{ Micro-scale } & \multicolumn{2}{|c|}{ Pilot-scale } & \multicolumn{2}{|c|}{ Demo-scale } & \multicolumn{2}{|c|}{ Commercial-scale } \\
\hline & Sim. & Exp. & Sim. & Exp. & Sim. & Exp. & Sim. & Exp. \\
\hline$Y_{\mathrm{CH} 4}$ & 0.00653 & 0.0145 & 0.01468 & 0.01643 & 0.03019 & 0.0322 & 0.0185 & 0.0201 \\
\hline$Y_{\mathrm{C} 2 \mathrm{H} 4}$ & 0.24373 & 0.2409 & 0.4432 & 0.4303 & 0.53928 & 0.4147 & 0.5179 & 0.3955 \\
\hline$Y_{\mathrm{C} 3 \mathrm{H} 6}$ & 0.37455 & 0.3825 & 0.3673 & 0.3457 & 0.31209 & 0.3748 & 0.3304 & 0.3921 \\
\hline$Y_{\mathrm{C} 3 \mathrm{H} 8}$ & 0.08697 & 0.0506 & 0.02874 & 0.03788 & 0.01361 & 0.0221 & 0.0167 & 0.0352 \\
\hline$Y_{\mathrm{C} 4}$ & 0.17351 & 0.1626 & 0.1073 & 0.0913 & 0.07497 & 0.1024 & 0.0826 & 0.1245 \\
\hline$Y_{\mathrm{C} 5}$ & 0.11471 & 0.1489 & 0.03877 & 0.07836 & 0.02985 & 0.0537 & 0.0339 & 0.0326 \\
\hline$Y_{(\mathrm{C} 2 \mathrm{H} 4+\mathrm{C} 3 \mathrm{H} 6)}$ & 0.6183 & 0.6234 & 0.8069 & 0.7760 & 0.8514 & 0.7895 & 0.8483 & 0.7876 \\
\hline $\mathrm{C}_{2} \mathrm{H}_{4} / \mathrm{C}_{3} \mathrm{H}_{6}$ & 0.6507 & 0.6298 & 1.2096 & 1.2449 & 1.728 & 1.1065 & 1.5674 & 1.0085 \\
\hline$w_{\text {coke }}$ & 0.82 & $\sim$ & 5.655 & 6 & 7.44 & 7.15 & 6.72 & 7.36 \\
\hline$\eta_{\mathrm{MeOH}}(\%)$ & 99 & 97.06 & 99.97 & 99.94 & 98.57 & 99.97 & 99.99 & 99.92 \\
\hline
\end{tabular}

The distribution of methanol on the axial cross section is displayed in Fig. 10. A large amount 
of methanol can be found in the region near the gas distributor for both reactors. For the pilot-scale reactor, almost no methanol remains above the elevation of $0.03 \mathrm{~m}$. While it can be found over the whole middle reaction zone of the commercial reactor due to the higher operating velocity. The axial profiles of $\mathrm{C}_{2} \mathrm{H}_{4}$ and $\mathrm{C}_{3} \mathrm{H}_{6}$ shown in Fig. 11 also confirm that the MTO reactions are almost completed in the region near the distributor. Compared to the pilot-scale reactor, there exists some amount of $\mathrm{C}_{2} \mathrm{H}_{4}$ and $\mathrm{C}_{3} \mathrm{H}_{6}$ below the distributor for the commercial-scale reactor, where the design of multi-pipe distributor allows downward injection of gas and hence occurrence of methanol conversion.

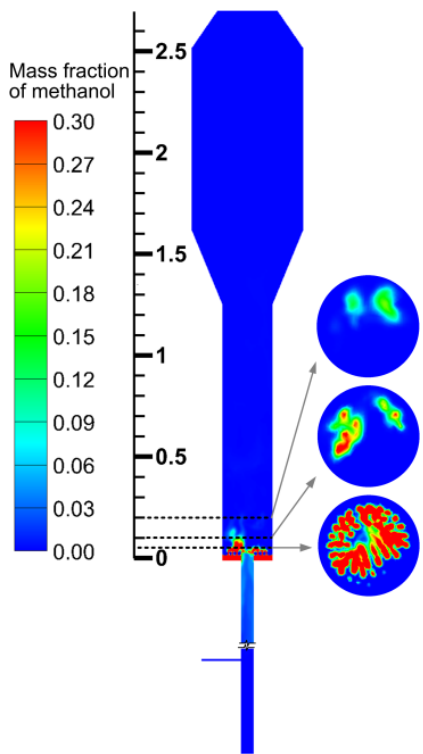

(a)

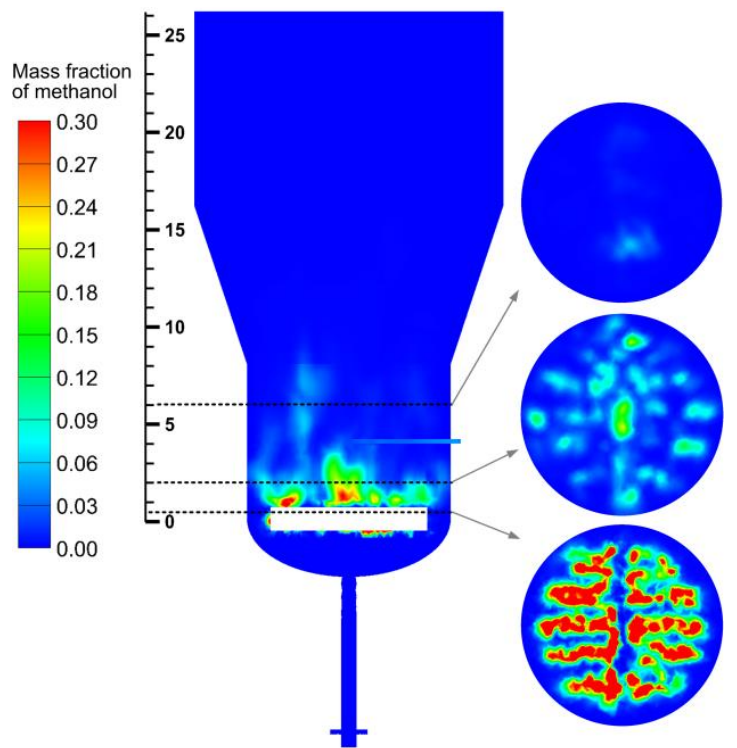

(b)

Fig. 10. Instantaneous distribution of mass fraction of methanol on the axial cross section (a) pilot-scale reactor; (b) commercial-scale reactor.
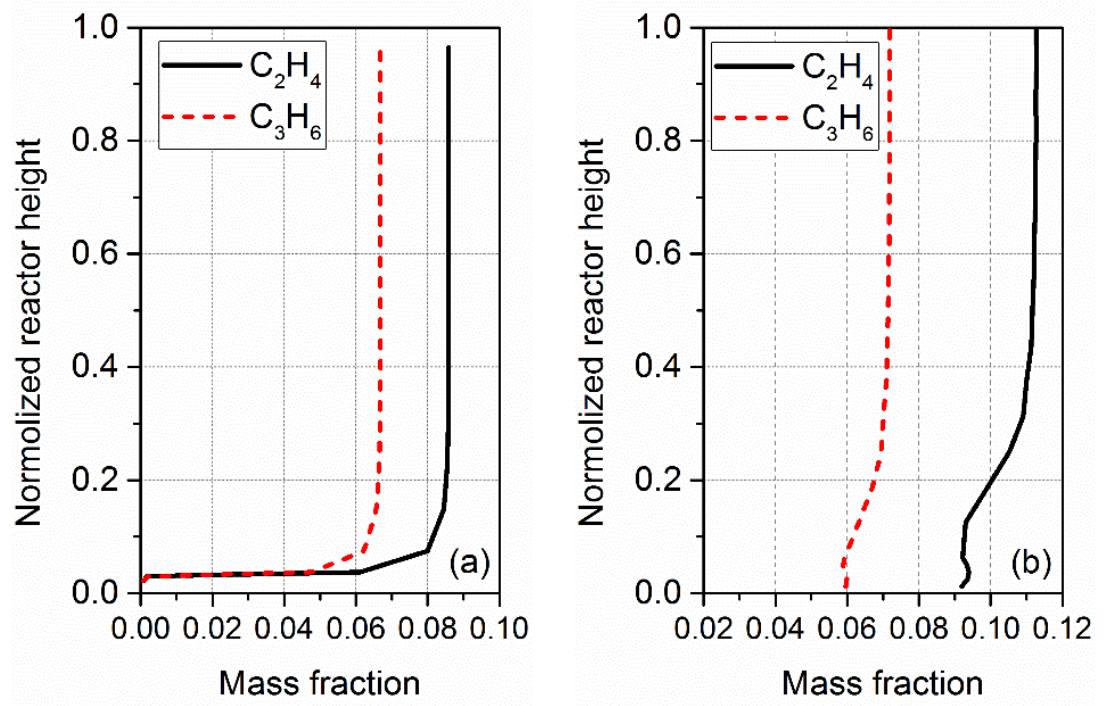

Fig. 11. Axial profiles of mass fraction of $\mathrm{C}_{2} \mathrm{H}_{4}$ and $\mathrm{C}_{3} \mathrm{H}_{6}$ in the main reaction zone: (a) pilot-scale reactor; (b) commercial-scale reactor. 


\subsection{Distribution of coke content}

Fig. 12 shows the instantaneous distribution of coke content. For the pilot-scale reactor, the distribution of coke content is uniform in the bottom but somewhat heterogeneous near the catalyst inlet owing to the inflow of fresh catalysts. More uniform distribution of coke content is found over the whole middle reaction zone for the commercial-scale reactor, and the influence of inflow of fresh catalyst can be almost neglected due to stronger mixing under turbulent fluidization with higher gas velocity. From the solid velocity contour in Fig. 8, we can guess that the catalyst particles below the distributor may stay longer in the reactor, thus leading to more coke deposited over particle surface. Indeed there could be significant coke content distribution even within a space as small as a computational cell, which is however homogenized by the TFM. So it is not surprising that the current TFM simulation predicts poorly the selectivity of ethylene and propylene that is strongly dependent on such local distribution of coke.

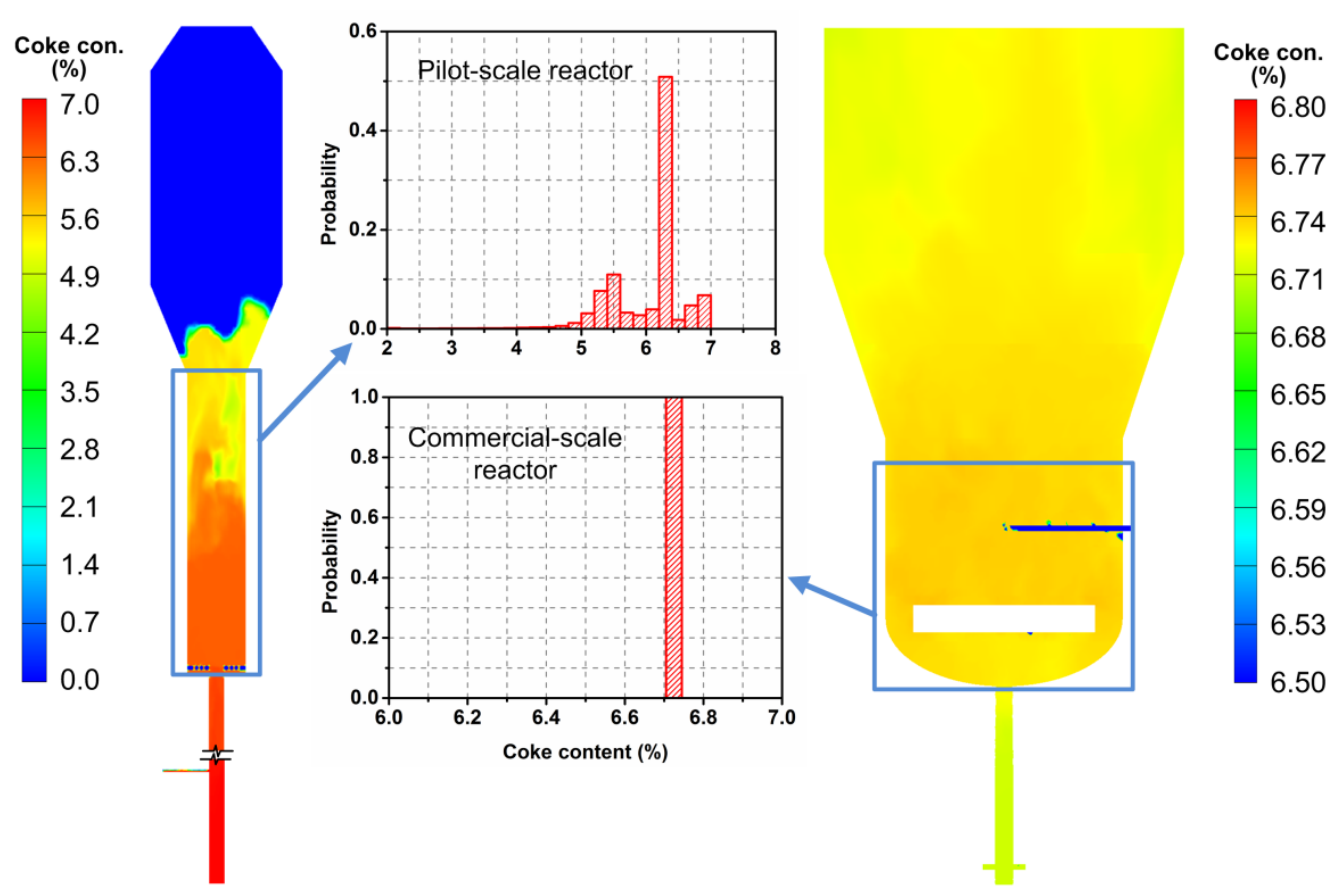

Fig. 12: The distribution of coke content over the main reaction zones of pilot-scale and industrial MTO reactors

\section{Conclusions and perspective}

By combining TFM and EMMS drag, hydrodynamic behaviors in different-sized DMTO reactors are generally captured. For reaction behaviors, the micro-scale and pilot-scale reactors are well predicted in terms of mass fractions of gaseous product, methanol conversion and the ratio of ethylene to propylene, but the simulations for the demo-scale and commercial-scale DMTO reactors fail to well predict the mass fractions of ethylene and propylene, especially the ratio of ethylene to propylene. There are some possible reasons. Firstly, these different DMTO reactors were operated in different fluidization regimes where characteristic flow structures may take quite different forms, however, the chemical kinetics were as usual obtained through fitting experimental data over micro-scale fluidized bed. So it can be expected that prediction discrepancy exists between for the small-and larger-scale reactors. Secondly, multiple flow 
regimes may coexist in the whole reaction zone of the large reactor due to the complex configuration of gas distributor. A large difference in fluidization state between above and below the distributor is readily detected in the commercial-scale reactor, thus probably leading to a certain distribution of coke. In this study, to speed up the reactive CFD simulation, a mean coke content predicted by CSTR model is employed as the initial value. This discrepancy between model and reality deserves further investigation.

To solve these problems, a multiphase flow model that allows consideration of different meso-scale structures, e.g., clusters and bubbles, is encouraged, to make it suitable for describing different fluidization regions involved in reactor scale-up process. The structure-dependent multi-fluid model (SFM) (Hong et al., 2012; Hong et al., 2013) represents such an effort but its local expression of stability condition needs further exploration. Additionally, the current initialization model based on CSTR approximation needs to be extended. Difference in coke content should be allowed in such initialization, thus the TFM with population balance model (PBM), or rather, directly a coarse-grained CFD-DEM approach such as DDPM (dense discrete phase model), can be applied more appropriately to tackle such situation with affordable computational resources. Finally, although the scale-up of fluidized bed reactors has long been regarded as a big challenge in chemical reaction engineering, the CFD-aided approach, if well modeled with consideration of meso-scale structures, can be expected to speed up the traditionally experiment-based scale-up process with much lower cost.

\section{Nomenclature}

$\begin{array}{ll}a & \text { inertial term, } \mathrm{m} / \mathrm{s}^{2} \\ C & \text { concentration, mol/L } \\ C_{\mathrm{D} 0} & \text { standard drag coefficient for an individual particle } \\ d_{\mathrm{b}} & \text { bubble diameter, } \mathrm{m} \\ d_{\mathrm{p}} & \text { particle diameter, } \mathrm{m} \\ f & \text { volume fraction of dense phase } \\ G_{\mathrm{s}} & \text { solid flux, } \mathrm{kg} /\left(\mathrm{m}^{2} \mathrm{~s}\right) \\ H_{\mathrm{D}} & \text { heterogeneity index }\left(H_{\mathrm{D}}=\beta / \beta_{0}\right) \\ I_{s} & \text { solids inventory, } \mathrm{g} \\ k_{\mathrm{i}} & \text { rate constant, } \mathrm{L} /\left(\mathrm{g}_{\mathrm{cat}} \cdot \mathrm{s}\right) \\ M & \text { molar weight, } \mathrm{g} / \mathrm{mol} \\ p & \text { pressure, Pa } \\ R_{\mathrm{i}} & \text { reaction rate, } \mathrm{g} /\left(\mathrm{g}_{\mathrm{cat}} \cdot \mathrm{s}\right) \\ R e & \text { Reynolds number, } \rho_{\mathrm{g}} \varepsilon_{\mathrm{g}}\left|\boldsymbol{u}_{\mathrm{g}}-\boldsymbol{u}_{\mathrm{s}}\right| d_{\mathrm{p}} / \mu_{\mathrm{g}} \\ \boldsymbol{u} & \text { real velocity, } \mathrm{m} / \mathrm{s} \\ U_{\mathrm{g}} & \text { superficial velocity, } \mathrm{m} / \mathrm{s} \\ w_{\text {coke }} & \text { coke content, } \mathrm{g} / 100 \mathrm{~g}_{\mathrm{cat}} \\ Y & \text { mass fraction }\end{array}$

Greek letters

$\beta \quad$ drag coefficient with structure in a control volume, $\mathrm{kg} /\left(\mathrm{m}^{3} \cdot \mathrm{s}\right)$

$\beta_{0} \quad$ drag coefficient without structure in a control volume, $\mathrm{kg} /\left(\mathrm{m}^{3} \cdot \mathrm{s}\right)$

$\varepsilon_{g} \quad$ voidage 


$\begin{array}{ll}\varepsilon_{s} & \text { solid volume fraction } \\ \eta & \text { conversion ratio }(\%) \\ \mu & \text { viscosity, } \mathrm{Pa} \cdot \mathrm{s} \\ \rho & \text { density, } \mathrm{kg} / \mathrm{m}^{3}\end{array}$

\section{Subscripts}

$\begin{array}{ll}\text { c } & \text { dense phase } \\ f & \text { dilute phase } \\ g & \text { gas phase } \\ s & \text { solid phase } \\ i & \text { lump in reaction kinetics }\end{array}$

(Bold characters are for vectors or tensors)

\section{Acknowledgement}

This work is financially supported by the National Natural Science Foundation of China under Grant nos. 21576263, 21625605 and 91334204, and the Youth Promotion Association CAS no.2015033.

\section{Appendix A}

Table A1. Fitting formulas of heterogeneity index $H_{\mathrm{D}}$ for the micro-scale DMTO reactor $\left(\mu_{\mathrm{g}}=2.5 \times 10^{-5} \mathrm{~Pa} \cdot \mathrm{s}, \rho_{\mathrm{g}}=0.32 \mathrm{~kg} / \mathrm{m}^{3}, d_{\mathrm{p}}=97 \mu \mathrm{m}, \rho_{\mathrm{s}}=1500 \mathrm{~kg} / \mathrm{m}^{3}, U_{\mathrm{g}}=0.09 \mathrm{~m} / \mathrm{s}, G_{\mathrm{s}}=0, \varepsilon_{\mathrm{mf}}=0.4\right)$

\begin{tabular}{ll}
\hline Fitting formulas & Range $\left(0.4 \leq \varepsilon_{g} \leq 1\right)$ \\
\hline$H_{\mathrm{D}}=0.10313+\frac{0.92767}{\left(1+\left(0.4063 / \varepsilon_{\mathrm{g}}\right)^{-105.3898}\right)^{0.1303}}$ & $\left(0.4 \leq \varepsilon_{g}<0.4677\right)$ \\
$H_{\mathrm{D}}=\left(-0.20694+1.28256 \varepsilon_{\mathrm{g}}\right)^{1.54493}$ & $\left(0.4677 \leq \varepsilon_{g}<0.9139\right)$ \\
$H_{\mathrm{D}}=1$ & $\left(0.9139 \leq \varepsilon_{g} \leq 1\right)$ \\
\hline
\end{tabular}

Table A2. Fitting formulas of heterogeneity index $H_{\mathrm{D}}$ for the pilot-scale DMTO reactor $\left(\mu_{\mathrm{g}}=2.43 \times 10^{-5} \mathrm{~Pa} \cdot \mathrm{s}, \rho_{\mathrm{g}}=0.4288 \mathrm{~kg} / \mathrm{m}^{3}, d_{\mathrm{p}}=97 \mu \mathrm{m}, \rho_{\mathrm{s}}=1500 \mathrm{~kg} / \mathrm{m}^{3}, U_{\mathrm{g}}=0.327 \mathrm{~m} / \mathrm{s}, G_{\mathrm{s}}=0, \varepsilon_{\mathrm{mf}}=0.4\right)$

\begin{tabular}{ll}
\hline Fitting formulas & Range $\left(0.4 \leq \varepsilon_{g} \leq 1\right)$ \\
\hline$H_{\mathrm{D}}=0.1443+\frac{1.6864}{1+\left(\varepsilon_{\mathrm{g}} / 0.4064\right)^{20.4805}}$ & $\left(0.4 \leq \varepsilon_{\mathrm{g}}<0.4924\right)$ \\
$H_{\mathrm{D}}=\left(-0.0999+0.9586 \varepsilon_{\mathrm{g}}\right)^{1.8008}$ & $\left(0.4924 \leq \varepsilon_{\mathrm{g}}<0.9505\right)$ \\
$H_{\mathrm{D}}=\left(1649.4591-1648.5453 \varepsilon_{\mathrm{g}}\right)^{-0.08597}$ & $\left(0.9505 \leq \varepsilon_{g} \leq 1\right)$ \\
\hline
\end{tabular}


Table A3. Fitting formulas of heterogeneity index $H_{\mathrm{D}}$ for the demo-scale DMTO reactor $\left(\mu_{\mathrm{g}}=2.67 \times 10^{-5} \mathrm{~Pa} \cdot \mathrm{s}, \rho_{\mathrm{g}}=0.65 \mathrm{~kg} / \mathrm{m}^{3}, d_{\mathrm{p}}=97 \mu \mathrm{m}, \rho_{\mathrm{s}}=1500 \mathrm{~kg} / \mathrm{m}^{3}, U_{\mathrm{g}}=0.9 \mathrm{~m} / \mathrm{s}, G_{\mathrm{s}}=0, \varepsilon_{\mathrm{mf}}=0.4\right)$

\begin{tabular}{ll}
\hline Fitting formulas & Range $\left(0.4 \leq \varepsilon_{g} \leq 1\right)$ \\
\hline$H_{\mathrm{D}}=0.0661+\frac{11.39945}{1+\left(\varepsilon_{\mathrm{g}} / 0.37219\right)^{32.98454}}$ & $\left(0.4 \leq \varepsilon_{g}<0.4708\right)$ \\
$H_{\mathrm{D}}=-1.1587+8.8391 \varepsilon_{g}-26.3964 \varepsilon_{g}^{2}+39.7346 \varepsilon_{g}^{3}-29.1181 \varepsilon_{g}^{4}+8.4392 \varepsilon_{g}^{5}$ & $\left(0.4708 \leq \varepsilon_{g}<0.9799\right)$ \\
$H_{\mathrm{D}}=\left(-15944.6+15944.6 / \varepsilon_{\mathrm{g}}\right)^{-0.2028}$ & $\left(0.9799 \leq \varepsilon_{g} \leq 1\right)$ \\
\hline
\end{tabular}

Table A4 Fitting formulas of heterogeneity index $H_{\mathrm{D}}$ for the commercial-scale DMTO reactor $\left(\mu_{\mathrm{g}}=2.563 \times 10^{-5} \mathrm{~Pa} \cdot \mathrm{s}, \rho_{\mathrm{g}}=0.7166 \mathrm{~kg} / \mathrm{m}^{3}, d_{\mathrm{p}}=97 \mu \mathrm{m}, \rho_{\mathrm{s}}=1500 \mathrm{~kg} / \mathrm{m}^{3}, U_{\mathrm{g}}=1.35 \mathrm{~m} / \mathrm{s}, G_{\mathrm{s}}=4 \mathrm{~kg} / \mathrm{m}^{2} \mathrm{~s}\right.$, $\varepsilon_{\mathrm{mf}}=0.4$ )

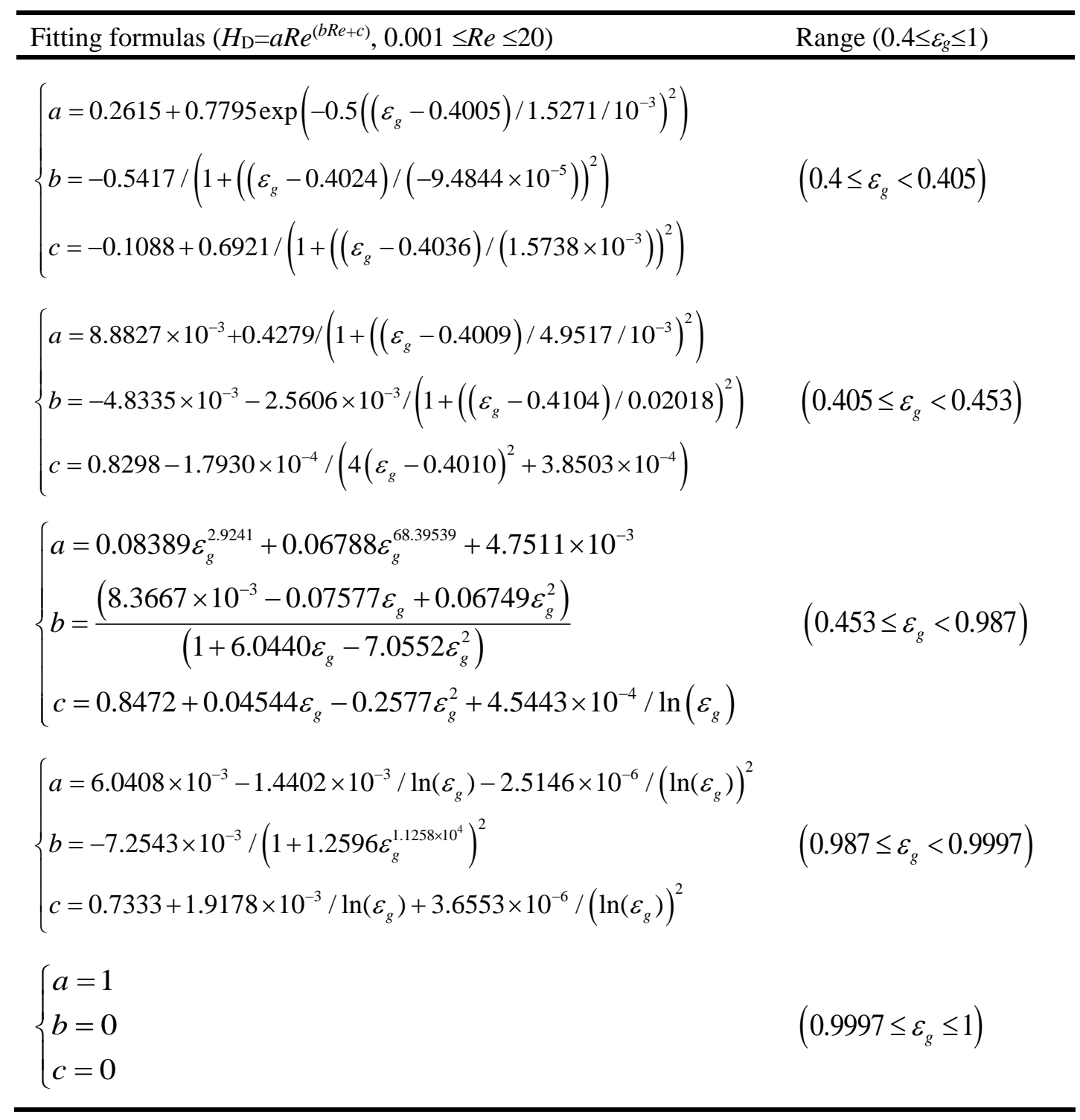




\section{References}

Alwahabi, S.M., Froment, G.F., 2004. Conceptual Reactor Design for the Methanol-to-Olefins Process on SAPO-34. Ind. Eng. Chem. Res. 43(17), 5112-5122.

ANSYS, I., 2013. ANSYS Fluent Theory Guide (release 15.0). <<http://www.ansys.com〉>.

Bos, A.N.R., Tromp, P.J.J., Akse, H.N., 1995. Conversion of Methanol to Lower Olefins. Kinetic Modeling, Reactor Simulation, and Selection. Ind. Eng. Chem. Res. 34(11), 3808-3816.

Chang, J., Meng, F., Wang, L., Zhang, K., Chen, H., Yang,Y., 2012. CFD investigation of hydrodynamics, heat transfer and cracking reaction in a heavy oil riser with bottom airlift loop mixer. Chem. Eng. Sci. 78, 128-143.

Gan, J., Zhao, H., Berrouk, A. S., Yang, C., Shan,H., 2011. Numerical Simulation of Hydrodynamics and Cracking Reactions in the Feed Mixing Zone of a Multiregime Gas-Solid Riser Reactor. Ind. Eng. Chem. Res. 50(20), 11511-11520.

Hong,K., Shi, Z., Ullah A., Wang,W., 2014. Extending the bubble-based EMMS model to CFB riser simulations. Powder Technol. 266, 424-432.

Hong, K., Shi, Z., Wang, W., Li, J., 2013. A structure-dependent multi-fluid model (SFM) for heterogeneous gas-solid flow. Chem. Eng. Sci. 99, 191-202.

Hong, K., Wang,W., Zhou, Q., Wang, J., Li, J., 2012. An EMMS-based multi-fluid model (EFM) for heterogeneous gas-solid riser flows: Part I. Formulation of structure-dependent conservation equations. Chem. Eng. Sci. 75(0), 376-389.

Li, J., Kwauk, M., 1994. Paticle-Fluid Two-Phase Flow: the Energy-Minimization Multi-Scale Method. Metallurgical Industry Press, Beijing.

Liu, C., Wang, W., Zhang, N., Li, J., 2015. Structure-dependent multi-fluid model for mass transfer and reactions in gas-solid fluidized beds. Chem. Eng. Sci. 122, 114-129.

Liu, Y., Chen, J. Ge, W., Wang, J., Wang, W., 2011. Acceleration of CFD simulation of gas-solid flow by coupling macro-/meso-scale EMMS model. Powder Technol. 212(1), 289-295.

Lopes, G. C., Rosa, L. M., Mori, M., Nunhez, J. R., Martignoni, W. P., 2011. Three-dimensional modeling of fluid catalytic cracking industrial riser flow and reactions. Comput. Chem. Eng. 35(11), 2159-2168.

Lu, B., Cheng, C., Lu, W., Wang, W., Xu,Y., 2013. Numerical simulation of reaction process in MIP riser based on multi-scale model (in Chinese). CIESC J. 64(6), 1983-1992.

Lu, B., Luo, H. Li, H., Wang,W., Ye, M., Liu, Z., Li, J., 2016. Speeding up CFD simulation of fluidized bed reactor for MTO by coupling CRE model. Chem. Eng. Sci. 143, 341-350.

Lu, B., Wang, W., Li, J., 2009. Searching for a mesh-independent sub-grid model for CFD simulation of gas-solid riser flows. Chem. Eng. Sci. 64(15), 3437-3447.

Lu, B., Wang, W., Li, J., 2011. Eulerian simulation of gas-solid flows with particles of Geldart groups A, B and D using EMMS-based meso-scale model. Chem. Eng. Sci. 66(20), 4624-4635.

Lu, B., Zhang, N., Wang, W. Li, J., Chiu, J.H., Kang, S.G., 2013. 3-D full-loop simulation of an industrial-scale circulating fluidized-bed boiler. AIChE J. 59(4), 1108-1117.

Luo, H., Lu, B., Wang,W., Zhang, J., Wu, H., 2017. A grid-independent EMMS/bubbling drag model for bubbling and turbulent fluidization. Submitted to Chem. Eng. J.

Mei, Y., Zhao, M., Lu, B., Chen, S. Wang, W., 2017. Numerical comparison of two modes of gas-solid riser operation: Fluid catalytic cracking vs CFB combustor. Particuology (http://dx.doi.org/10.1016/j.partic.2016.05.007)

Milioli, C. C., Milioli, F.E., Holloway,W., Agrawal, K., Sundaresan, S., 2013. Filtered two-fluid models 
of fluidized gas-particle flows: new constitutive relations. AIChE J. 59(9), 3265-3275.

Rüdisüli, M., Schildhauer,T.J., Biollaz, S.M.A., van Ommen, J.R., 2012. Scale-up of bubbling fluidized bed reactors - A review. Powder Technol. 217(0), 21-38.

Schoenfelder, H., Hinderer, J., Werther, J., Keil, F. J., 1994. Methanol to olefins-prediction of the performance of a circulating fluidized-bed reactor on the basis of kinetic experiments in a fixed-bed reactor. Chem. Eng. Sci. 49(24), 5377-5390.

Shah, M. T., Utikar, R.P., Pareek, V.K., Evans G.M., Joshi, J.B., 2016. Computational fluid dynamic modelling of FCC riser: A review. Chem. Eng. Res. Des. 111, 403-448.

Shi, Z., Wang, W., Li, J., 2011. A bubble-based EMMS model for gas-solid bubbling fluidization. Chem. Eng. Sci. 66(22), 5541-5555.

Soundararajan, S., Dalai, A. K., Berruti, F., 2001. Modeling of methanol to olefins (MTO) process in a circulating fluidized bed reactor. Fuel 80(8), 1187-1197.

Tian, P., Wei, Y., Ye, M., Liu, Z., 2015. Methanol to Olefins (MTO): From Fundamentals to Commercialization. ACS Catal. 5(3), 1922-1938.

Tong, J., Li, J., 1982. Computation for thermophysical properties of fluid (In Chinese). Tsinghua University Press.

Wang, W., Ge, W., Yang N., Li, J., 2011. Meso-Scale Modeling-The Key to Multi-Scale CFD Simulation. Adv. Chem. Eng. 40, 1-58.

Wang, W., Li, J., 2007. Simulation of gas-solid two-phase flow by a multi-scale CFD approach-extension of the EMMS model to the sub-grid level. Chem. Eng. Sci. 62(1-2), 208-231.

Wang, W., Lu, B., Zhang, N., Shi, Z. Li, J., 2010. A review of multiscale CFD for gas-solid CFB modeling. Inter. J. Multiphase Flow 36(2), 109-118.

Wen, C.Y., Yu, Y.H., 1966. Mechanics of fluidization. Chem. Eng. Symposium Series 62(62), 100-111.

Xue, Q., Heindel T.J., Fox, R. O. 2011. A CFD model for biomass fast pyrolysis in fluidized-bed reactors. Chem. Eng. Sci. 66(11), 2440-2452.

Yang, N., Wang, W., Ge, W., Li, J., 2003. Choosing structure-dependent drag coefficient in modeling gas-solid two-phase flow. China Particuology 1, 38-41.

Ye, M., Li, H., Zhao, Y., Zhang, T., Liu, Z., 2015. MTO Processes Development: The Key of Mesoscale Studies. Adv. Chem. Eng. 47, 279-335.

Zhao, M., Lu, B., Wang,W., Huang, W., Li, J. 2013. Influence of initial distributions on hydrodynamic simulation of gas-solids riser (in Chinese). CIESC J. 64(3), 811-817.

Zhao, Y., Li, H., Ye, M., Liu, Z., 2013. 3D Numerical Simulation of a Large Scale MTO Fluidized Bed Reactor. Ind. Eng. Chem. Res. 52, 11354-11364

Zhu, C., Jun,Y., Patel, R., Wang, D., Ho, T.C., 2011. Interactions of flow and reaction in fluid catalytic cracking risers. AIChE J. 57(11), 3122-3131.

Zhu, L.T., Ye, M., Luo, Z.H. 2016. Application of Filtered Model for Reacting Gas-Solid Flows and Optimization in a Large-scale Methanol-to-olefin Fluidized Bed Reactor. Ind. Eng. Chem. Res. (http://dx.doi.org/10.1021/acs.iecr.6b02819)

Zhuang, Y.Q., Chen, X.M. Luo, Z.-H., Xiao, J., 2014. CFD-DEM modeling of gas-solid flow and catalytic MTO reaction in a fluidized bed reactor. Comput. Chem. Eng. 60, 1-16. 